\title{
Photoinduced charge separation in aqueous solution of porphyrin-quinone end-capped poly(methacrylic acid)
}

\author{
Szczepan Zapotoczny), *), Fumio Kataoka ${ }^{2)}$, Maria Nowakowska ${ }^{1), *)}$
}

DOI: dx.doi.org/10.14314/polimery.2014.095

\author{
Dedicated to Professor Stanistaw Penczek on the occasion of his $80^{\text {th }}$ birthday
}

\begin{abstract}
Photoinduced charge separation from porphyrin $(\mathrm{P})$ to benzoquinone $(\mathrm{Q})$ moieties covalently attached to the opposite chain ends of poly(methacrylic acid) (PMMA) was studied. The effect of polymer chain length, $\mathrm{pH}$ and ionic strength of the aqueous solution on the rate constant of charge separation and efficiency of $\mathrm{P}^{+\bullet}-\mathrm{Q}^{-\bullet}$ radical ion pair formation was determined.
\end{abstract}

Keywords: poly(methacrylic acid), anionic polymerization, porphyrin, benzoquinone, photoinduced electron transfer, photoinduced charge-separation, radical-ion pair, electron paramagnetic resonance (EPR).

\section{Fotoindukowana separacja ładunku pomiędzy porfiryną i chinonem przyłączo- nymi kowalencyjnie na przeciwnych końcach łańcucha poli(kwasu metakrylo- wego)}

\begin{abstract}
Streszczenie: Badano proces fotoindukowanej separacji ładunku pomiędzy cząsteczkami porfiryny (P) i benzochinonu (Q), kowalencyjnie przyłączonymi na przeciwnych końcach łańcucha poli(kwasu metakrylowego) (PMMA). Określono wpływ długości łańcucha, pH, siły jonowej wodnych roztworów polimeru na wartość stałej szybkości separacji ładunku i wydajności tworzenia pary rodniko-jonów $\mathrm{P}^{+\bullet}-\mathrm{Q}^{-\bullet}$.

Słowa kluczowe: poli(kwas metakrylowy), polimeryzacja anionowa, porfiryna, benzochinon, fotoindukowane przenoszenie elektronu, fotoindukowana separacja ładunku, para rodniko-jonowa, elektronowy rezonans paramagnetyczny (EPR).
\end{abstract}

\section{INTRODUCTION}

Photoinduced charge separation is one of the most fascinating and the most important photophysical phenomenon which allows to convert the energy of light photon to the electrical or chemical ones. The process is proceeded by photoinduced electron transfer between suitable electronically excited electron donor and electron acceptor molecules. Photoinduced electron transfer can occur when redox process within an electron donor and acceptor molecule pair is thermodynamically favorable. The efficiency of that process is additionally affected by the mutual orientation and the distance between electron donor and acceptor [1-5]. Understanding of the photoinduced charge separation is essential for further development of photovoltaic solar cells, photocatalytic processes, organic photochemical synthesis. The nature

\footnotetext{
1) Faculty of Chemistry, Jagiellonian University, 30-060 Kraków, Ingardena 3, Poland.

2) Production Engineering Research Laboratory, Hitachi Ltd., 292 Yoshida-cho, Toksuka-ku, Yokohama 244, Japan.

*) Authors for correspondence; e-mail: zapotocz@chemia.uj.edu.pl, maria.nowakowska@chemia.uj.edu.pl
}

utilizes solar light in photochemical process known as photosynthesis, which is essential for life on our planet photoinduced charge separation is the primary step in this process. Photosynthesis is mastered in green parts of plants with exceptional efficiency and precision. Majority of natural photosynthetic systems consist of antenna complexes, in which chlorophyll pigment molecules are specifically arranged within the protein membrane. The charge separation is achieved through an unique spatial arrangement of the pigments and elements of the electron transport chain. Electronic excitations that reach the reaction centers are converted to chemical energy in the form of charge separation within chlorophyll-quinone molecules across the photosynthetic membrane. In these organized arrays electrons flow rapidly $(<\mathrm{ms})$ over distances as great as $20 \AA$, with little loss of energy [6, 7]. The photosynthesis in plants is a source of inspiration for scientists to engineer non-natural systems that similarly convert light into chemical potential or electrical energy. In order to achieve that goal there is a need to get the better understanding of these phenomena. There have been recently some successful attempts to produce the 'artificial leaf' [6], to extract the natural pigments/reaction centres, modify them and study their activity in vitro, or to extract photosystems from the plant, introduce them to the syn- 
thetic membranes and follow their activity in vitro [7-10]. It has been realized, however, that mechanistic studies require simpler and well defined systems. Thus, considerable attempts have been directed on developing the synthetic models of the reaction center or covalently linked bichromphoric porphyrin-quinone (P-Q) systems. They have been used to explain how variables such as distance, orientation, type of solvent, and exothermicity effect the rates of charge separation and a rate of back reaction, the charge recombination [11-13].

Interesting studies have been initiated some time ago in the research laboratories of late Professor James E. Guillet at the University of Toronto, on photoinduced electron transfer between the chromophore units attached to the polymer chain. The results of preliminary studies on polyelectrolytes decorated with chromophores for which the photophysical studies could be carried out in aqueous solutions were especially interesting [14-17]. These studies have been continued in our laboratories. The current paper presents the photoinduced electron transfer and charge separation in aqueous solution of poly(methacrylic acid) polymers characterized by the well defined length of the chain having the chain ends capped with porphyrin and quinone moieties. The effect of $\mathrm{pH}$ and ionic strength of aqueous polymer solution on the conformation of the polymer chain and end-to-end distance, (what translates to P-Q distance) directly influencing the efficiency of charge separation, was evaluated. It was assumed that in the systems studied the tenability of the electron transfer rates can be achieved which is not available in P-Q systems attached by the rigid linkages with fixed dimensions.

\section{EXPERIMENTAL PART}

\section{Materials}

Series of polymers used in this work, varied with number of methacrylic acid repeating units (MA) and containing porphyrin $(\mathrm{P})$ and quinone $(\mathrm{Q})$ at the opposite chain ends were prepared by anionic polymerization. As reference systems the respective polymers with the same number of MA units but having porphyrin $(\mathrm{P})$ and phenol $(\mathrm{PhOH})$ were obtained. Detailed description of the synthesis and physicochemical characterization of these polymers has been presented earlier [17].

\section{Methods of testing}

- UV spectra of the samples were measured using a Hewlett-Packard 8451A diode-array spectrophotometer.

- FT-IR spectra were obtained on a Nicolet 5DX spectrometer.

- ${ }^{1} \mathrm{H}$ NMR spectra were measured using Varian XL400 spectrometer or a Gemini 200 spectrometer. A XL400 spectrometer was used for characterization of the polymers.
-Steady-state fluorescence spectra of the samples were recorded at room temperature on an SLM fluorescence spectrometer. Transient fluorescence decay curves were measured using a single-photon counting apparatus. The samples were bubbled with argon prior the measurements for $30 \mathrm{~min}$. The samples were excited at $420 \mathrm{~nm}$ and the emission was measured at $650 \mathrm{~nm}$. The nonlinear iterative deconvolution technique was applied to fit the decay curves.

- The $\mathrm{pH}$ value for each sample was monitored by using a digital $\mathrm{pH}$ meter (Corning $\mathrm{pH} /$ ion meter model 150). For $\mathrm{pH}$ adjustment, $0.1 \mathrm{~N} \mathrm{NaOH}$ and $0.1 \mathrm{~N} \mathrm{HCl}$ solutions were used.

- GPC analyses were performed on a Waters Liquid Chromatography system using a Dupont Bimodal column pair and tetrahydrofuran (THF) as an elluent $\left(1 \mathrm{~cm}^{3} / \mathrm{min}\right)$. Both spectrofluorometer (Bio-Systems, Model 900) and refractometer (Waters, Model R410) were used as detectors. Uniform poly(methyl methacrylate) standards of molecular weights of 4100 to 60000 were used for calibration.

- Elemental analysis were carried out by Galbraith Laboratories, Inc., Knoxville, Tennessee, USA.

- Electron paramagnetic resonance measurements (EPR) were conducted on a Varian E-12 EPR spectrometer equipped with a temperature controller and quartz window. For EPR measurements at X-band ( $\sim 9 \mathrm{GHz})$, solutions were placed in 4-mm Pyrex tubes, which were introduced into a quartz dewar of the temperature controller in the EPR cavity. The measurements were conducted at $195 \mathrm{~K}$. The samples were irradiated in the EPR cavity using a $100 \mathrm{~W}$ Xenon lamp mounted in a PTI 02-A1000 water cooled housing with $f 4.5$ reflector (focal point at $288.4 \mathrm{~mm}$ from the front of the housing) and a glass cutoff filter $(\lambda>400 \mathrm{~nm}$ or $\lambda>300 \mathrm{~nm})$.

2,2-Di(4-tert-octylphenyl)-1-picrylhydrazyl (DPPH) was used as a standard. In order to determine the $g$ factor precisely for the free radicals formed in the polymer solutions, the spectrum of DPPH powder was recorded after each measurement. The concentrations of the radicals formed in the polymer solutions were calculated from the relative intensities of the EPR signals. The EPR spectrometer was calibrated using several DPPH solutions in carbon tetrachloride.

\section{RESULTS AND DISCUSSION}

\section{Polymers characterization}

The studies were carried out using three PMA polymers characterized by different numbers of the repeating units (47, 94 and 277, respectively), capped with 5-(4'-carbonylphenyl)-10,15,20-tri( $p$-tolyl)-porphine $(\mathrm{P})$ at one chain end and with 2-(1'-phenylhexyl)-p-benzoquinone $(\mathrm{Q})$ on the other [Q-(MA) $\left.)_{\mathrm{n}}-\mathrm{P}\right]$. The polymers capped with $P$ at one chain end and with 2-(1'-phenylhexyl)phenol $(\mathrm{PhOH})$ at the other one served as the reference com- 
T a b l e 1. Characteristics of the studied polymers*)

\begin{tabular}{l|c|c|c|c|c|c|c}
\hline \multicolumn{1}{c|}{ Polymer } & $M_{n}$ & $\begin{array}{c}R_{n}, \AA \\
\mathrm{pH}=4.5\end{array}$ & $\begin{array}{c}R_{n}, \AA \\
\mathrm{pH}=9\end{array}$ & $\begin{array}{c}R_{H}, \AA \\
\mathrm{\AA}\end{array}$ & $\begin{array}{c}R_{e x} \AA \\
\AA\end{array}$ & $\begin{array}{c}\varphi_{\mathrm{f}} \cdot 10^{2} \pm 0.3 \\
\mathrm{pH}=4.5\end{array}$ & $\begin{array}{c}\varphi_{\mathrm{f}} \cdot 10^{2} \pm 0.2 \\
\mathrm{pH}=9\end{array}$ \\
\hline PhOH-(PMA) $)_{47}-\mathrm{P}$ & 4400 & 9.3 & 60 & 39 & 119 & 5.9 & 15.9 \\
Q-(PMA) & 4400 & 9.3 & 60 & 39 & 119 & 3.3 & 15.8 \\
PhOH-(PMA) & 8400 & 13.1 & 88 & 55 & 238 & 6.0 & 14.7 \\
Q-(PMA) & 8400 & 13.1 & 88 & 55 & 238 & 3.7 & 14.1 \\
PhOH-P & 24100 & 22.6 & 146 & 95 & 700 & 9.3 & 14.0 \\
Q-(PMA) & 24100 & 22.6 & 146 & 95 & 700 & 8.1 & 14.0 \\
\hline
\end{tabular}

*) $M_{n}$ - number average molecular weight of polymer; $R_{n}-$ the root-mean-square end-to-end distance of the polymer chain; $R_{H}-$ hydrodynamic radius of the polymer chain; $R_{e x}$ - theoretical length of fully extended chain; $\varphi_{\mathrm{f}}-$ quantum yield of $\mathrm{P}$ fluorescence in aqueous polymer solution.

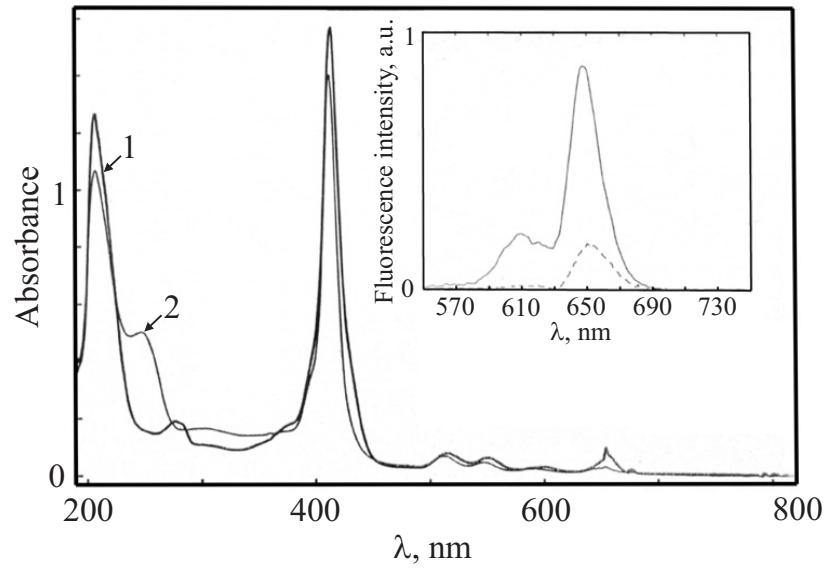

Fig. 1. Electronic absorption spectra of $\mathrm{PhOH}-(\mathrm{PMA})_{94}-\mathrm{P}(1)$ and $\mathrm{Q}-(\mathrm{PMA})_{94} \mathrm{P}(2)$ in methanol solution $\left(c_{p o l}=2 \cdot 10^{-5} \mathrm{M}\right.$, cell thickness $l=1 \mathrm{~cm})$, insert: fluorescence spectra of $\mathrm{Q}-(\mathrm{PMA})_{94}-\mathrm{P}$ in aqueous solution at $\mathrm{pH}=4$ (dashed line) and $\mathrm{pH}=9.5$ (solid line) $\left(c_{p o l}=\right.$ $3 \cdot 10^{-5} \mathrm{M}, \lambda_{\text {ex }}=420 \mathrm{~nm}$ )

pounds. The dispersity of the polymers was about 1.1. Polymer characteristics are presented in Table 1 . The comparison of the electronic absorption and emission spectra of Q-(MA) $)_{n}-P$ polymers in methanol solutions (see Fig. 1) with the model porphyrin and quinone chromophores indicated that the attachment of $P$ and $Q$ to the polymer chain does not perturbed their electronic structures.

\section{Photophysical studies}

All polymers studied are soluble in water. As expected, their absorption and emission characteristics are strongly $\mathrm{pH}$ dependent (see Fig. 1, insert). That can be explained considering the $\mathrm{pH}$-induced changes in the degree of ionization of MA units in the polymer backbone and the shift in the equilibrium of protonation of porphyrin free-base. The emission spectra measured at the excitation in the porphyrin Soret band $(\lambda \sim 400 \mathrm{~nm})$ display two bands with the maxima at $654 \mathrm{~nm}$ and $603 \mathrm{~nm}$ whose relative intensities are strongly $\mathrm{pH}$ dependent. It was observed that the fluorescence intensity in the acidic solu- tions for the quinone-containing polymers are lower than for the respective polymers containing phenol at the chain ends. That suggest that porphyrin is quenched by the quinone moiety in these systems as a results of interactions of $\mathrm{P}$ and $\mathrm{Q}$ being in a short distance allowing the occurrence of the electron transfer process. These observations are in agreement with the results of model studies which have shown that the efficient electron transfer in the P-Q molecular pair can occur when their separation distance is less than $20 \AA$. Thus, it is not surprising that there is no $\mathrm{P}$ quenching by $\mathrm{Q}$ in basic polymer solutions where, due to ionization of MA units, the polymer chain becomes extended and the distance between $\mathrm{P}$ and $\mathrm{Q}$ is to large to make electron transfer possible (see Table 1). That was confirmed by the observation of the ionic strength effect on the quantum yield of porphyrin fluorescene in $\mathrm{Q}-(\mathrm{MA})_{\mathrm{n}}-\mathrm{P}$ polymers at various $\mathrm{pH}$. It was observed that an increase in ionic strength of the solution results in reduction of porphyrin fluorescence, but the extent of that process is dependent on the length of the polymer chain and on $\mathrm{pH}$ of the solution. The changes are much more pronounced in basic than in the acidic solutions. That reflects the changes in the conformation of the polymer chain induced by the screening of the charged carboxyl groups on backbone by ions of the salt $(\mathrm{NaCl})$ added.

Based on the measurements of the porphyrin fluorescence quantum yields in the polymer solutions the rate constant of the photoinduced electron transfer and charge separation $\left(k_{c s}\right)$ can be calculated using the equation [18]:

$$
k_{c s}=\left[\left(\varphi_{\text {rel }} / \varphi\right)-1\right] / \tau_{\text {ref }}
$$

where: $\varphi_{\text {rel }}-$ fluorescence quantum yield of the porphyrin reference system, 5-(4-carboxyphenyl)-10,15,20-tritolylporphine $(\mathrm{TCP})\left(\varphi_{\text {rel }}=0.13\right.$ for $0.01 \mathrm{M}$ solution in $\mathrm{CH}_{2} \mathrm{Cl}_{2}$ ) [19]; $\varphi-$ fluorescence quantum yield of $\mathrm{Q}-(\mathrm{MA})_{\mathrm{n}}-\mathrm{P}$ polymer, $\tau_{\text {ref }}-$ fluorescence lifetime of the porphyrin reference system, $\mathrm{TCP}\left(\varphi_{\text {ref }}=9.2 \mathrm{~ns}\right.$ in $\mathrm{CH}_{2} \mathrm{Cl}_{2}$ solution) [19].

The values of the respective rate constants for the polymers at various ionic strength and $\mathrm{pH}$ values are presented in Table 2. 
$\mathrm{T}$ a b l e 2. The rate constants $\left(k_{c s}\right)$ of photoinduced charge separation in aqueous acidic and basic polymer solutions determined from fluorescence measurements at various ionic strength $(I)$

\begin{tabular}{c|c|c|c|c|c|c}
\hline \multirow{2}{*}{$I \cdot 10^{3}, \mathrm{M}$} & \multicolumn{9}{|c}{$k_{c s} \cdot 10^{-7}, \mathrm{~s}^{-1}$} \\
\cline { 2 - 7 } & $\begin{array}{c}\mathrm{Q}-(\mathrm{PMA})_{47}-\mathrm{P} \\
\mathrm{pH}=4\end{array}$ & $\begin{array}{c}\mathrm{Q}-(\mathrm{PMA})_{47}-\mathrm{P} \\
\mathrm{pH}=9.5\end{array}$ & $\begin{array}{c}\mathrm{Q}-(\mathrm{PMA})_{94}-\mathrm{P} \\
\mathrm{pH}=4\end{array}$ & $\begin{array}{c}\text { Q-(PMA) } \\
\mathrm{pH}-\mathrm{P}=9.5\end{array}$ & $\begin{array}{c}\mathrm{Q}-(\mathrm{PMA})_{277}-\mathrm{P} \\
\mathrm{pH}=4\end{array}$ & $\begin{array}{c}\mathrm{Q}-(\mathrm{PMA})_{277}-\mathrm{P} \\
\mathrm{pH}=9.5\end{array}$ \\
\hline 1.3 & 18.0 & 0 & 14.0 & 4.0 & 3.0 & 0 \\
2.3 & 18.5 & 8.2 & 13.0 & 4.1 & 1.5 & 0 \\
10.5 & 20.1 & 75.0 & 12.9 & 4.5 & 1.0 & 7.2 \\
100 & 29.3 & 150.0 & 12.1 & 11.2 & 3.3 & 98.0 \\
500 & 35.1 & 385.0 & 11.0 & 96.0 & 2.4 & 99.1 \\
1000 & 42.0 & 860.0 & 13.2 & 335.0 & 3.2 & 288.0 \\
2000 & 56.3 & 900.0 & 24.2 & 350.0 & 3.4 & 292.0 \\
\hline
\end{tabular}

\section{Electron paramagnetic resonance measurements}

EPR measurements were performed for all Q-(MA) ${ }_{n}-P$ polymers in frozen aqueous solution (at $193 \mathrm{~K}$ ) at several $\mathrm{pH}$ and ionic strength values. EPR signals were detected in all the studied samples. They differ, however, in their intensities. Typical light-induced EPR spectrum for $\mathrm{Q}-(\mathrm{MA})_{94}-\mathrm{P}$ in aqueous solutions at $\mathrm{pH}=13$ is presented in Fig. 2. The characteristic, asymmetric signal of $g=2.0037 \pm 0.00002$ appeared in the sample [20, 21]. The $g$ factor is in excellent agreement with the value calculated based on the assumption that it is a spin-exchange average of $\mathrm{P}^{+\bullet}(g=2.0025)[22]$ and $\mathrm{Q}^{-\bullet}(g=2.0047)[20,22]$. The value of $g=2.0037$ was reported earlier for the radical pair $\mathrm{P}^{+\bullet}-\mathrm{Q}^{-\bullet}$ in bichromophoric low-moleclar-weight systems [22] and in the copolymer of acrylic acid with 5-(10,15,20-tritolylporphinyl)phenyl methacrylate and 2-isopropenylanthraquinone [21].

The values of the amplitudes $(A)$ and peak-to-peak line widths $\left(\Delta H_{p p}\right)$ for the Q-(MA) $)_{94}$-P polymer at several different $\mathrm{pHs}$ are summarized in Table 3 . The highest intensities of the EPR signal assigned to $\mathrm{P}^{+\bullet}-\mathrm{Q}^{-\bullet}$ and the

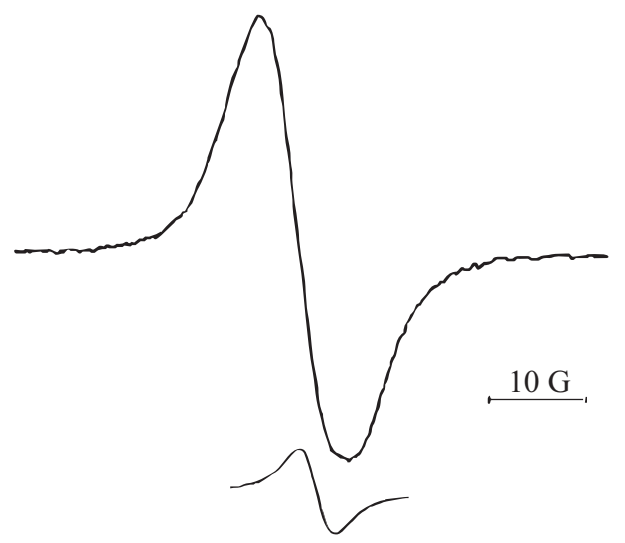

Fig. 2. Typical light-induced EPR signal for Q-(PMA) ${ }_{94}-\mathrm{P}$ at $\mathrm{pH}=13\left(c_{p o l}=3 \cdot 10^{-3} \mathrm{M}, I=0.39 \mathrm{M}\right.$, frozen aqueous medium, $T=$ $193 \mathrm{~K}$, modulation amplitude $1.6 \mathrm{G}$, microwave power $5 \mathrm{MW}$, microwave frequency $9.153 \mathrm{GHz}$ ) concentrations of these species were observed for the polymer solutions in $\mathrm{pH}$ range 6 to 10. Interestingly, signals of high intensities were detected in alkaline solutions e.g., at $\mathrm{pH}=13$ (see Fig. 2 ) or $\mathrm{pH}=10.2$ (see Fig. 3), where the methacrylic acid units in a polymer backbone are almost fully ionized. The effect can be rationalized considering the high ionic strength of these solutions. Assuming a total ionization of the MA units and taking into account the concentration of the polymer used $\left(3 \cdot 10^{-3} \mathrm{M}\right)$ and concentration of $\mathrm{NaOH}$ added to adjust $\mathrm{pH}$, the ionic strength of the solution of $\mathrm{pH}=10.2$ was estimated to be about 0.3 . At this level of the ionic strength the rate constant of photoinduced electron transfer followed by charge separation, determined from the fluorescence measurements was about $5 \cdot 10^{8} \mathrm{~s}^{-1}$. The appearance of the strong signal shows that the recombination process is inhibited under these conditions. It was shown, however, that further increase in ionic strength results in reduction of the intensity of the

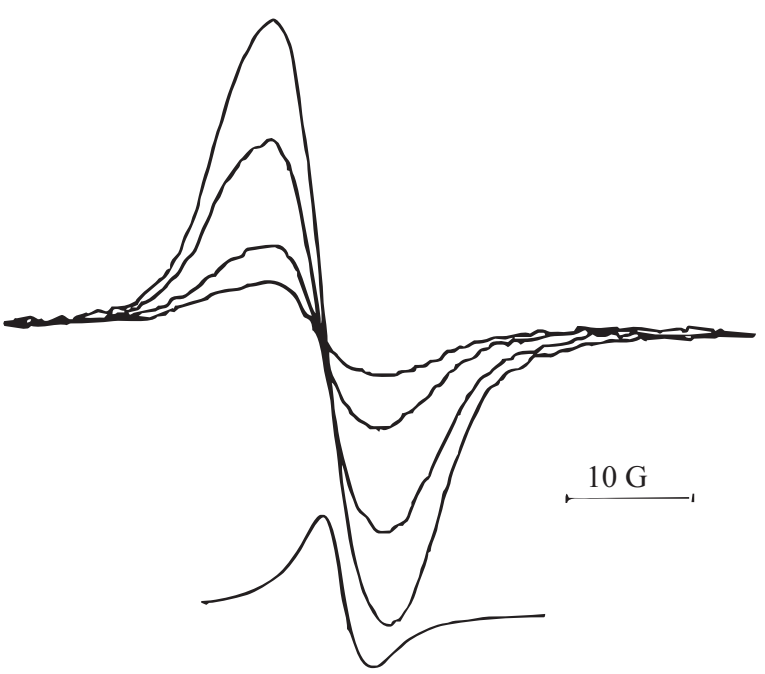

Fig. 3. The light induced EPR signals for Q-(PMA) $)_{94}-\mathrm{P}$ at several different ionic strengths $(I)$ - from top: $I=0.29,0.33,1.29,2.29 \mathrm{M}$ $\left(c_{p o l}=3 \cdot 10^{-3} \mathrm{M}, \mathrm{pH}=10.2\right.$, frozen aqueous medium, $T=193 \mathrm{~K}$, modulation amplitude $1.6 \mathrm{G}$, microwave power $5 \mathrm{~mW}$, microwave frequency $9.162 \mathrm{GHz}$ ) 
EPR signal (see Fig. 3) although it increases the $k_{c s}$ values. This indicates the growing importance of the reverse reaction. Thus, by adjusting the $\mathrm{pH}$ and ionic strength of the solution one can optimize the polymeric system to obtain a higher efficiency of charge separation.

As it was mentioned earlier, higher intensities of the EPR signal assigned to the $\mathrm{P}^{+\bullet}-\mathrm{Q}^{-\bullet}$ were observed for the polymers at a higher degree of ionization (in neutral and alkaline solutions). This may be explained considering both the more efficient charge separation and the existence of conditions favoring the charge stabilization. Possible mechanism of the charge stabilization involves the occurrence of the repulsive Coulombic interactions between an anion radical $\mathrm{Q}^{-\bullet}$ and the carboxyl anions surrounding the porphyrin moiety $\left(\mathrm{P}^{+\bullet}\right)$ thus preventing their recombination.

T a b l e 3. EPR data for Q-(PMA $)_{94}-\mathrm{P}$ aqueous solutions at several different $\mathrm{pH}$ values*)

\begin{tabular}{c|c|c|c|c|c}
\hline $\mathrm{pH}$ & $2 Y^{\prime}$ & $\Delta H_{p p,} \mathrm{G}$ & $I$ & $c_{P^{+\bullet}-Q^{-}} \cdot 10^{5}, \mathrm{M}$ & $c_{P^{+\bullet}-Q^{-}} / c_{p^{\prime}}^{0} \%$ \\
\hline 2.8 & 3.7 & 6.0 & 66.5 & 0.4 & 1.8 \\
3.6 & 3.6 & 6.5 & 75.0 & 0.5 & 2.1 \\
4.5 & 20.0 & 6.5 & 422.5 & 2.7 & 12.6 \\
6.0 & 12.0 & 9.5 & 618.0 & 4.0 & 15.5 \\
9.5 & 13.0 & 9.7 & 580.0 & 4.5 & 17.5 \\
10.2 & 13.1 & 9.3 & 566.5 & 3.7 & 16.0 \\
13.0 & 9.0 & 9.3 & 389.0 & 2.5 & 11.0 \\
\hline
\end{tabular}

*) Polymer concentration $c=3 \cdot 10^{-3} \mathrm{M}$, initial concentration of porphyrin $c_{P}{ }^{0}=2.28 \cdot 10^{-4} \mathrm{M}, T=193 \mathrm{~K} ; 2 Y^{\prime}-$ the peak-to-peak first derivative amplitude; $\Delta H_{p p}-$ the peak-to-peak width; $I$ is a relative intensity of the signal, $I \sim Y\left(\Delta H_{p p}\right)$ [23].

It was observed that the intensities of the EPR signals for all polymers decrease considerably in solutions of low $\mathrm{pH}$ (e.g. solution at $\mathrm{pH}=2.8$, see Table 3$)$. This may be due to the low efficiency of charge separation, lack of stabilization via repulsive electrostatic interactions and the occurrence of secondary processes with participation of the primarily formed radical pair. The occurrence of the secondary reactions can be easily proven by simple compa-

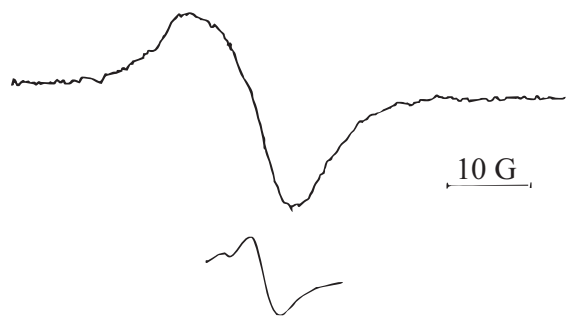

Fig. 4. Photoinduced EPR signal for $\mathrm{Q}-(\mathrm{PMA})_{94}-\mathrm{P}$ in a frozen acidic aqueous medium $\left(c_{p o l}=3 \cdot 10^{-3} \mathrm{M}, T=193 \mathrm{~K}\right.$, modulation amplitude $1.6 \mathrm{G}$, microwave power $5 \mathrm{~mW}$, microwave frequency $9.162 \mathrm{GHz})$ rison of the EPR signals obtained in alkaline (Fig. 2) and in acidic solutions (see Fig. 4). The line shapes of these two signals are noticeably different. That can be explained considering difference in the surrounding of the radical-ion pair formed. One can observe, however, that the spectra recorded in the acidic solutions seem to contain two components. The appearance of the second component can result from the hydrogenation of the primarily formed $\mathrm{Q}^{-\bullet}$ to benzosemiquinone radical, $\mathrm{QH}^{\bullet}$. Thus, although in acidic solution the concentration of the originally formed radical pair is low, the protonation of $\mathrm{Q}^{-}$ probably assists in preventing the electron back-transfer. In acidic solutions, similarly to the case described previously in alkaline medium, the increase in ionic strength results in a decrease of the total intensity of the EPR signals. This can be caused by acceleration of charge recombination.

The intensities of the EPR signals in both alkaline and acidic solutions are dependent on the length of the polymer chain. The net efficiency of charge separation increases in the following order: Q-(MA) $)_{277}-\mathrm{P}, \mathrm{Q}-(\mathrm{MA})_{47}-\mathrm{P}$, $\mathrm{Q}-(\mathrm{MA})_{94}-\mathrm{P}$. This can be explained considering lower rate constants for electron transfer in the polymer with the longest chains $(\mathrm{MA})_{277}$ and the higher probability of charge recombination in the case of the polymer with short chains $(\mathrm{MA})_{47}$.

The observed dependence of the intensity of EPR signals on the polymer chain length, $\mathrm{pH}$ and ionic strength of the solution confirms that the charge separation observed in aqueous Q-(MA) $)_{n}-\mathrm{P}$ solutions is really an intramolecular process.

In the control experiments performed using phenol-capped polymer, $\mathrm{PhOH}-(\mathrm{MA})_{94}-\mathrm{P}$, it was found that under the same conditions as for quinone-capped polymers, for phenol-capped one there was no EPR signal detected.

It was also demonstrated that the process is light induced since no EPR signal was observed in any of the samples studied in the dark. Analysis of the data presented in Table 3 shows that in the case of Q-(MA) $)_{94}-\mathrm{P}$ polymer, about $18 \%$ of the porphyrin originally present can be converted to the stable $\mathrm{P}^{+\bullet}-\mathrm{Q}^{-\bullet}$ radical pair. In the experiment in which radiation of spectral distribution closer to that of solar light, $\lambda>300 \mathrm{~nm}$, was applied (light was absorbed almost exclusively by porphyrin, Q absorbed only $3 \%$ of radiation at $324 \mathrm{~nm}$ where transmission of the filter is about $20 \%$ ), the typical EPR signal for $\mathrm{P}^{+\bullet}-\mathrm{Q}^{-\bullet}$ was also observed [23].

\section{CONCLUSIONS}

The steady-state fluorescence spectra and EPR measurements performed in aqueous solutions of poly(methacrylic acid) with covalently attached porphyrin and benzoquinone moieties [Q-(MA) $-\mathrm{P}$ ] clearly demonstrate the occurrence of photoinduced electron transfer from the lowest excited singlet state of porphyrin to the qui- 
none. Both the rate constant of charge separation and the efficiency of formation of a stable radical pair $\mathrm{P}^{+\bullet}-\mathrm{Q}^{-}$ can be controlled by changes in the length of the polymer chain, as well as, by changing the $\mathrm{pH}$ and ionic strength of the aqueous polymer solutions. The highest values of $k_{c s}$ were found for the polymer with shortest chain length, Q-(MA) ${ }_{47}-\mathrm{P}$, at high $\mathrm{pH}$ and ionic strength $(\mathrm{pH}=9, \mathrm{I}=$ $1 \mathrm{M})$. However, the highest efficiency of formation of stable radical pairs was observed for Q-(MA) ${ }_{94}-\mathrm{P}$, in neutral and basic solutions, at relatively high ionic strength. This can be rationalized taking into account the high values of $k_{c s}$ under these conditions and the operation of the protection mechanism $\left(\mathrm{P}^{+\bullet}\right.$ are protected against recombination with $\mathrm{Q}^{-\bullet}$ by negatively charged ionized carboxyl groups). The importance of this protective mechanism was demonstrated by findings that further increase in ionic strength of the solution, although accompanied by further increases in the $k_{c s}$ values results in a decrease in the concentration of the stable $\mathrm{P}^{+\bullet}-\mathrm{Q}^{-\bullet}$ radical ion pair. This probably occurs because of neutralization of the charged carboxylic units. In acidic solutions, protonation of $\mathrm{Q}^{-\bullet}$ is believed to inhibit charge recombination. The generally higher values of $k_{c s}$ and higher concentration of stabilized free radical in basic medium may be also due to the more appropriate mutual orientation of the chromophores. At low $\mathrm{pH}$ the unionized PMA chain adopts the compact conformation with the polymer chain ends clustered together due to the unbalanced hydrophobic interactions. At high $\mathrm{pH}$ that conformation is broken via ionization of the methacrylic acid units. Thus, the chain can adopt a new equilibrium conformation in which the electron donor $(\mathrm{P})$ and electron acceptor $(\mathrm{Q})$ molecules are not clustered. Partial or total neutralization of the charges distributed along the polymer chain bring the P and Q chromophors closer, thus allowing for electron transfer and charge separation.

\section{ACKNOWLEDGMENTS}

MN is grateful to the late Professor James E. Guillet for the opportunity to participate in many interesting and challenging research projects related to the photophysics and photochemistry of polymeric systems.

The authors would like to thank Polish Ministry of Science and Higher Education for the financial support in the form of Ideas Plus grant (IdP2011 000561).

\section{REFERENCES}

1. Marcus R. A.: J. Phys. Chem. 1965, 43, 679.

2. Weller A. Z.: Phys. Chem. (Wiesbaden) 1982, 133, 93.

3. Wasielewski M. R., Niemczyk M. P.: J. Am. Chem. Soc. 1984, 106, 5043.

4. Wasielewski M. R., Niemczyk M. P., Svec W. A., Pewitt E. B.: J. Am. Chem. Soc. 1985, 107, 1080.

5. Joran A. R., Leland B. A., Felker P. M., Zewail A. H., Hopfield J. J., Dervan P. B.: Nature 1987, 327, 508.

6. Nocera D. G.: Acc. Chem. Res. 2012, 45, 767.

7. Patwardhan S., Sengupta S., Siebbeles L. D. A., Würthner F., Grozema F. C.: J. Am. Chem. Soc. 2012, 134, 16147.

8. Springer J. W., Parkes-Loach P. S., Reddy K. R., Krayer M., Jiao J., Lee G. M., Niedzwiedzki D. M., Harris M. A., Kirmaier C., Bocian D. F., Lindsey J. S., Holten D., Loach P. A.: J. Am. Chem. Soc. 2012, 134, 4589.

9. Kloz M., Pillai S., Kodis G., Gust D., Moore T. A., Moore A. L., van Grondelle R., Kennis J. T. M.: J. Am. Chem. Soc. 2011, 133, 7007.

10. Westenhoff S., Paleček D., Edlund P., Smith P., Zigmantas D.: J. Am. Chem. Soc. 2012, 134, 16484.

11. Fox M. A.: Adv. Photochem. 1986, 13, 237.

12. Wasielewski M. R.: Chem. Rev. 1992, 92, 435.

13. Weaver M. J.: Chem. Rev. 1992, 92, 463.

14. Guillet J. E., Takahashi Y., McIntosh A. R., Bolton J. R.: Macromolecules 1985, 18, 1788.

15. Liu G., Guillet J. E., Al-Takrity E. T. B., Jenkins A. D., Walton D. R. M.: Macromolecules 1991, 24, 68.

16. Liu G., Guillet J. E., Vlegels M., Goethals E. J.: Macromolecules 1991, 24, 4094.

17. Nowakowska M., Kataoka F., Guillet J. E.: Macromolecules 1996, 29, 1600.

18. Nowakowska M., White B., Guillet J. E.: Macromolecules 1989, 22, 3903.

19. Wasielewski M. R., Niemczyk M. P.: J. Am. Chem. Soc. 1984, 106, 5043

20. Sulivan P. D., Bolton J. R., Geiger Jr. W. E.: J. Am. Chem. Soc. 1970, 92, 4176.

21. Guilet J. E., Takahashi Y., McIntosh A. R., Bolton J. R.: Macromolecules 1985, 18, 1788.

22. McIntosh A. R., Siemiarczuk A., Bolton J. R., Stillman M. J., Ho T.-H., Weedon A. C.: J. Am. Chem. Soc. 1983, 105, 7224.

23. Wertz J. E., Bolton J. R.: “Electron Spin Resonance Elementary Theory and Practical Applications", McGraw-Hill, New York 1972. 